\title{
Some Historadiographs of Human Dentin Structures
}

\author{
by \\ Sohiti ISOKAWA*, Ichiro SATOMURA*, Takahiko MISU*, \\ Tai HASEGAWA* and Hiroshi HONDA**
}

Recent advancement in the historadiographic techniques has made it possible to observe the calcified tissues with comparative ease, thus enabling a fair number cf researchers to conduct work on the fine structures of bony and dental tissues. Although there is much published literature on dentin structures by the use of historadiography, an effort which compares our knowledge gained by the historadicgraphy with that of optical microscopy is yet scarce. NALBANDIAN et al. [1], in 1960, reported their comparison of photomicrographs of opaque dentin with historadiographs. In 1964, HARCOURT [2] published a study on the sclerotic dentin in terms of historadiographs. TODA et al. (1966) [3], members of our department, published the historadiographs and photomicrcgraphs of the exposed dentinal tubules of human dentin recently.

The present study is concerned with the historadiographs of some human dentin structures that have been fairly familiar to us optical microscopically.

\section{Materials and Method}

By way of materials, dentins from the human teeth were used for this study. After the dentins were dehydrated with alcohol, these dentins were embedded in plastic and cut with a sectioning machine either longitudinally or transversely. The sections were carefully ground planoparallelly on an Arkansas stone until they were $20-100 \mu$ thick. The contact radiographs of the sections placed in contact with the emulsion surface of Eastman Kodak film, type 649-0, were taken with X-radiation at $4 \mathrm{kV}$. and $1 \mathrm{~mA}$. using a Softex CMR X-ray machine.

The sections and their historadiographs were observed under a microscope.

\section{Historadiographic Observations}

Fig. 1 is a historadiograph of the dentinal tubules in dentin surrounding the dental pulp and the tubules seen here have not suffered from peritubular hypercalcification. These tubules are quite frequently seen in dentin around the root canal. On the other hand, Fig. 2 gives a historadiograph of dentin which has a high degree of peritubular hypercalcified zone. As is seen here, the dentinal tubules are in most cases much narrowed inside through the peritubular hypercalcification. In some cases, the tubules are completely blocked with mineral salts. It is usual that sclerotic dentin gives this kind of histographic image. Fig. 3 is a historadiograph of root transparent dentin,

* 磯川 宗七, 里邨一郎, 三須 孝彦, 長谷川 泰： Department of Anatomy, Nihon Univ. School of Dentistry

** 本田 博： Department of Conservative Dentistry, Nihon Univ. School of Dentistry 


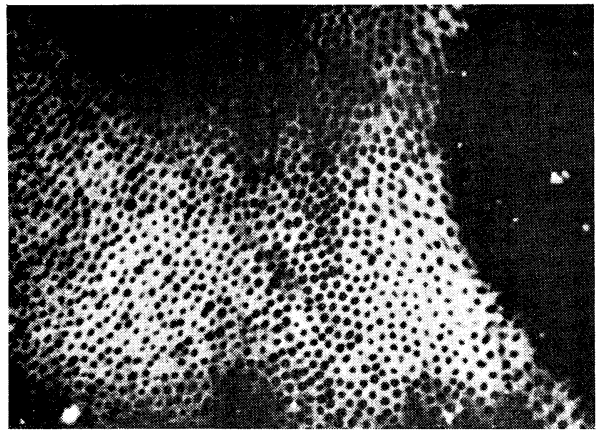

Fig. 1

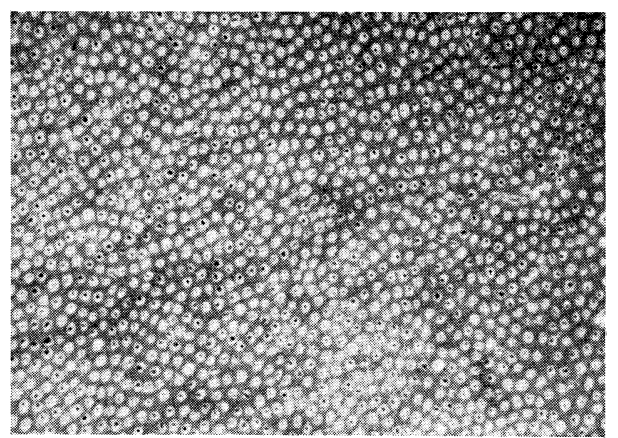

Fig. 2

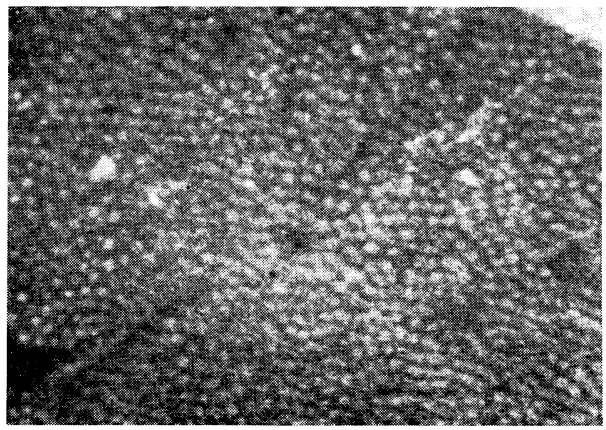

Fig。 3

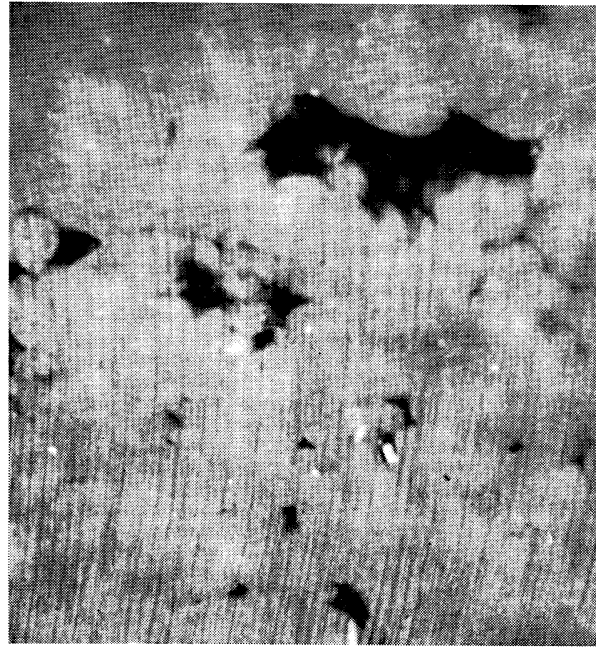

Fig. 4 (A)

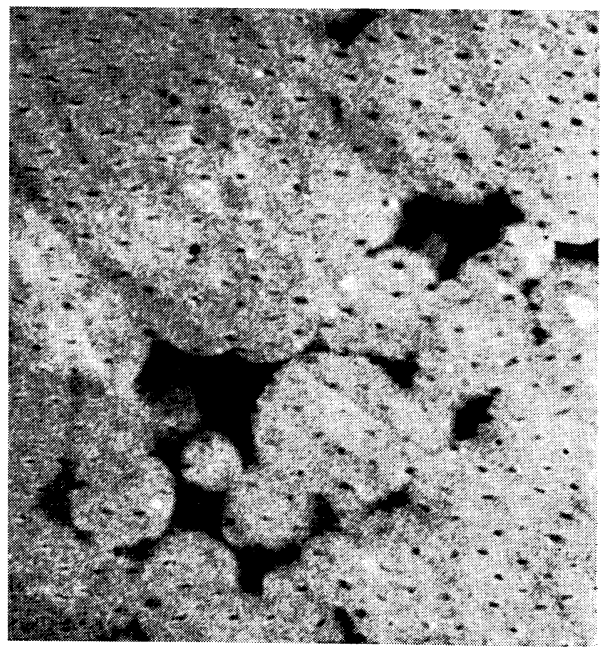

Fig. $4 \quad$ (B) 
where the majority of tubules are obstructed with mineral salts which make them transparent. As it is generally understocd, an interglobular space is that part of dentin which is not calcified and even historadiographically the abscrption of X-ray is not observed (Fig. 4). Figs. 5 and 6 are historadiographs of dentin suffering from attriticn and its dentinal tubules. What is indicated by an arrow on the photomicrcgraph of ground section $(\mathbf{A})$ is shown historadingraphically as $\mathbf{B}$. Fig. $5(\mathbf{B})$ which is dentin suffering from the attrition shows a high degree of peritubular calcification, while Fig. 6(B) reveals no calcification of the dentinal tubules at all.

As is known from these images, dentin underneath the structure suffering from the attrition has not always highly calcified tubules in all cases.

In many cases, the peritubular hypercalcified zone of tubules in this region has well developed. Similar to Figs. 5 and 6 , the arrowed spot in a photcmicrcgraph (A) of Fig. 7 is historadiographically represented in $\mathbf{B}$. The right upper portion which lacks in the tubules corresponds to a secondary dentin cone. Many tubules completely obstructed by mineral salts were frequently observed as if surrounding this secondary dentin cone.

As regards Fig. $8(\mathbf{A})$ is a photomicrograph of ground section while the remaining $\mathbf{B}, \mathbb{C}$ and $\mathbf{D}$ are all historadiographs. In the latter, $\mathbb{C}$ is a partial enlargement of $\mathbf{B}$ and $\mathbf{D}$ portrays the cross section of tubules in $\mathbf{C}$. When the photomicrograph (A) and historadiograph $(\mathbf{B})$ are compared, it is of interest to note an abrasion owing to the abuse of tooth-brush in the lower layer of dentin as contrasted with the formation of secondary dentin cone. Fig. $8(\mathbf{C})$ reveals the manner of X-ray absorption fairly well and differences in the X-ray absorption seen here may be accounted for by differences in the development of peritubular hypercalcified zone as given in $\mathbf{D}$.

\section{Discussions}

The fact that the peritubular hypercalcified zone is not observable in dentinal tubules adjacent to the dental pulp was already made public by VAN HUYSEN [4] in 1961. ATKINSON and HARCOURT [5] confirmed this and also reported that there were not found hypercalcified dentinal tubules in the root dentin. From a vast amount of published literature, it is hard to believe that dentinal tubules in the root portion have no peritubular hypercalcified zone. However, many investigators are inclined to the view that as compared with those of roct dentin the dentinal tubules of crown dentin is more apt to undergo calcification. This has been showed by IsokAWA and SHIMoYAmA [6,7] with the teeth of several mammals. Therefore, no peritubular hypercalcified zones are often found in that part of dentin which is around the root canal. In the sclerotic dentin, there are sporadically observed dentinal tubules which have not undergone any peritubular hypercalcification. This fact seems to be universal with all sclerotic dentin (TODA et al., [3]).

As FEILER (1923) [8] and others pointed out, transparent dentin is caused by the closure of dentinal tubules by unstable calcium salts, our historadiographs here also revealed that all the tubules had been closed in the majority of cases.

In this connection, an interesting finding is that the attritional portion of dentin in some cases had undergone less peritubular calcification as compared with other dentin portions. This should claim our future research effort for its elucidation.

As is learned from a series of photographs in Fig. 8, peritubular calcification seems to be a chief causating factor for the sclerosis of dentin. This thinking has been supported by FEILER and many others, but for its full explanation we must wait for future endeavors. 


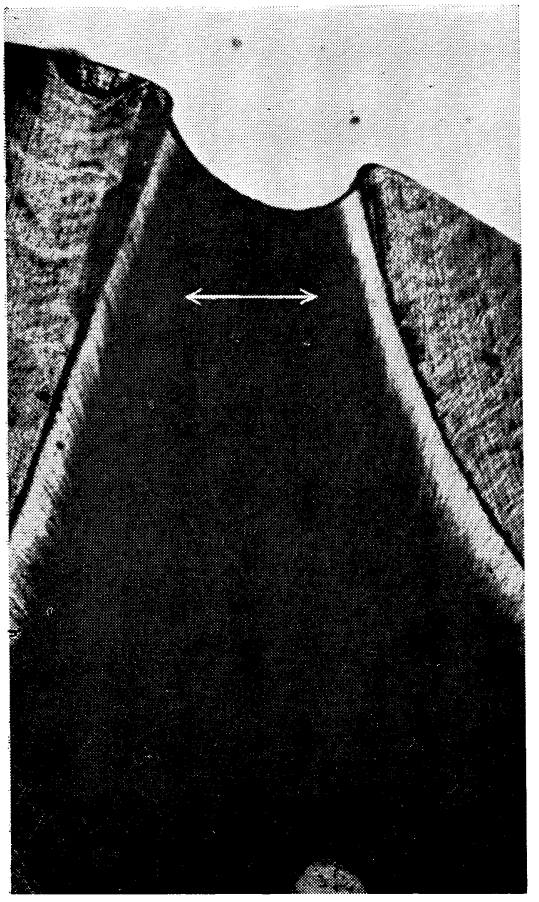

Fig. 5 (A)

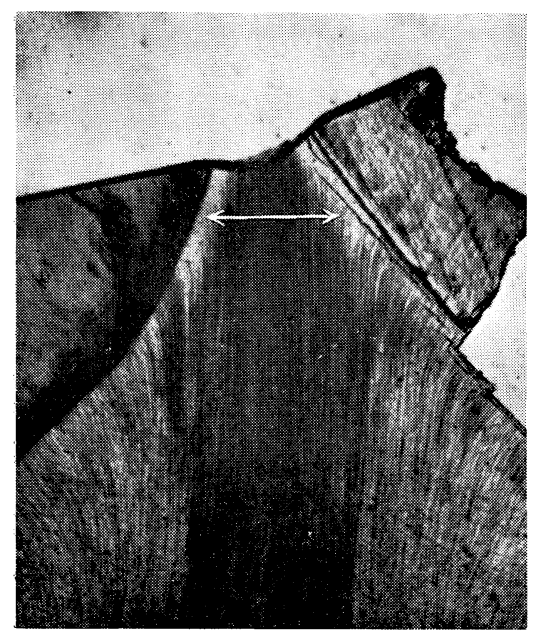

Fig. 6 (A

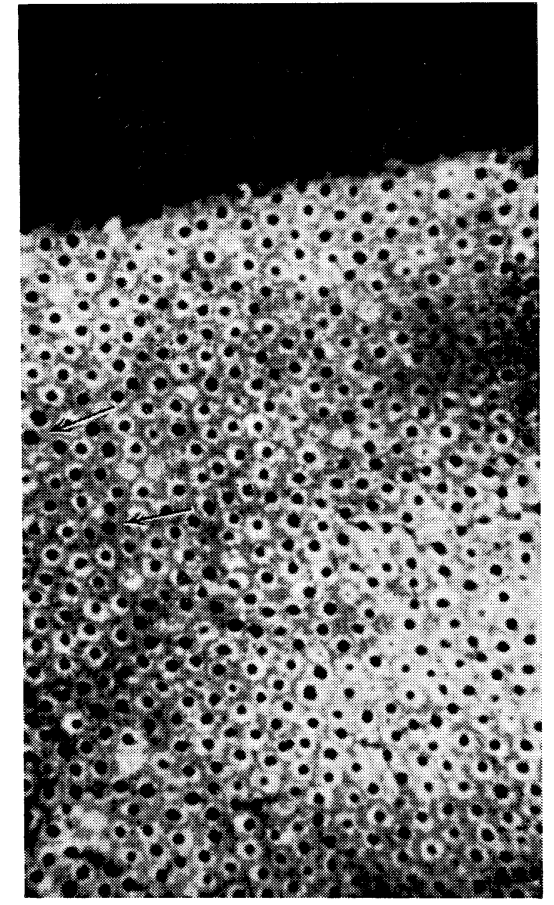

Fig. 5 (B)

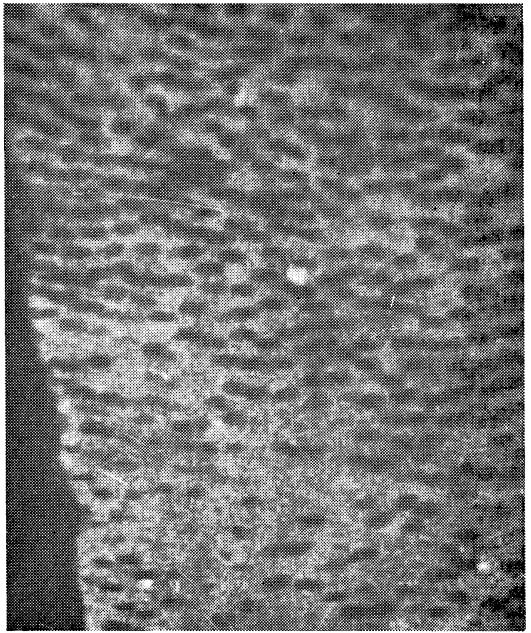

Fig. $6 \quad$ (B) 


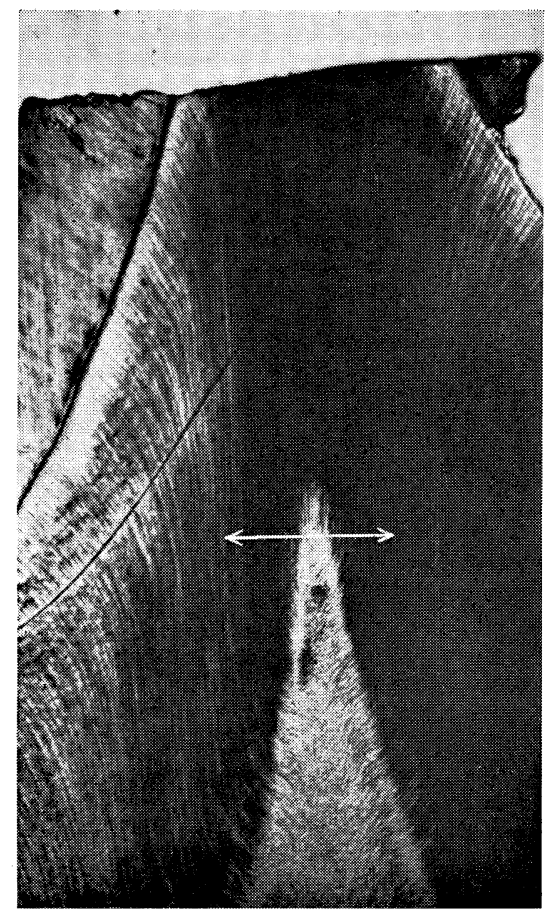

Fig. $\quad 7 \quad(\mathbf{A})$

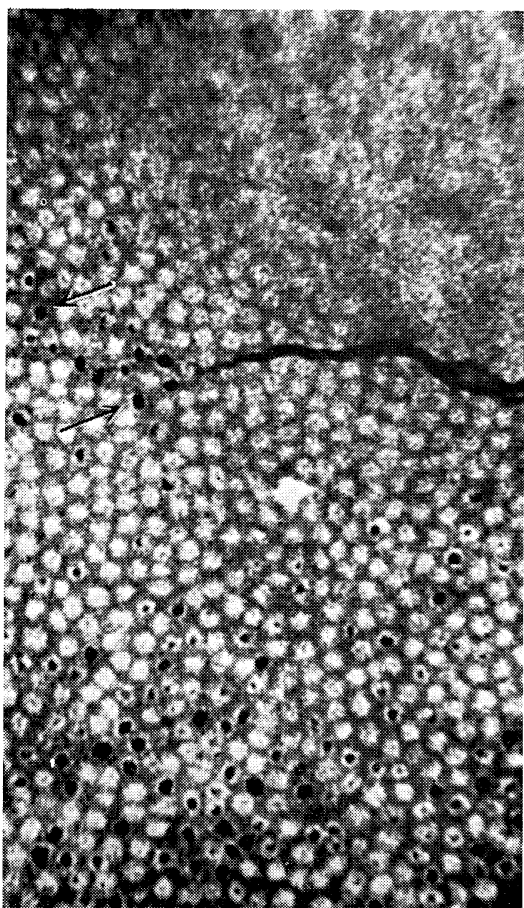

Fig. 7 (B)

\section{Conclusions}

Our findings of historadiographs have confirmed our previous understanding of the dentin structures by the light microscope to be essentially true. A chief cause for the sclerosis of dentin seems to be the peritubular calcification found frequently in the dentinal tubules. However, the present study did not go far enough to elucidate the mechanism of peritubular calcification. The lower layer of dentin under attrition which appears opaque radiographically contained some tubules highly calcified and others not undergoing calcification at all.

\section{References}

[1] Nalbandian, J., Ganzales, F. and Sognnaes, F. R. : Sclerotic Age Changes in Root Dentin of Human Teeth as observed by Optical, Electron and X-ray Microscopy, J. dent. Res., 39 : 598-607 (1960).

[2] Harcourt, J. K. : Further Observations on the Peritubular Translucent Zone in Human Dentin, Austral. dent. J., 9 : 387-392 (1964).

[ 3 ] Toda, Y., Tsuruoka, Y., Wada, N., Tsubouchi, M., Hasegawa, T. and Nishihara, T. : Historadiography of Exposed Dentinal Tubules of Human Dentin (Japanese), Nihon Univ. dent. J., 40 : 541-547 (1966).

[4] Van Huysen, G.: The Microstructure of Young Dentin, Arch. oral Biol., 3 : 157-160 (1961).

[5] Atkinson, H. and Harcourt, J. K. : Some Observations on the Peritubular Translucent Zones in Human Dentin, Austral. dent. J., 6 : 194-197 (1961). 


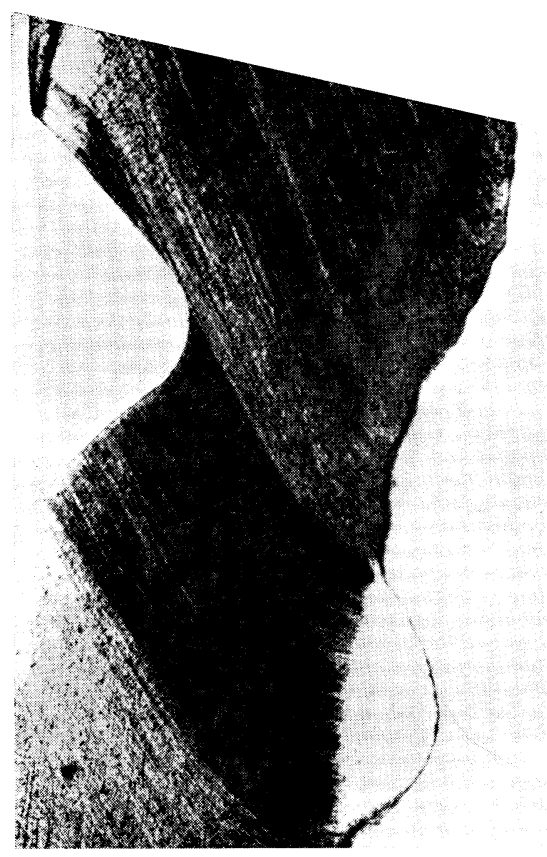

Fig. 8 (A)

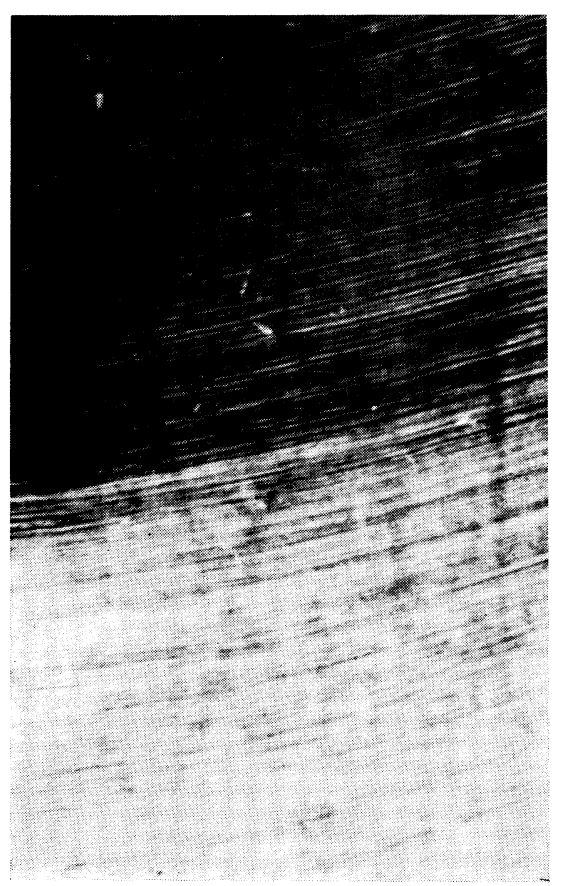

Fig, 8 (C)

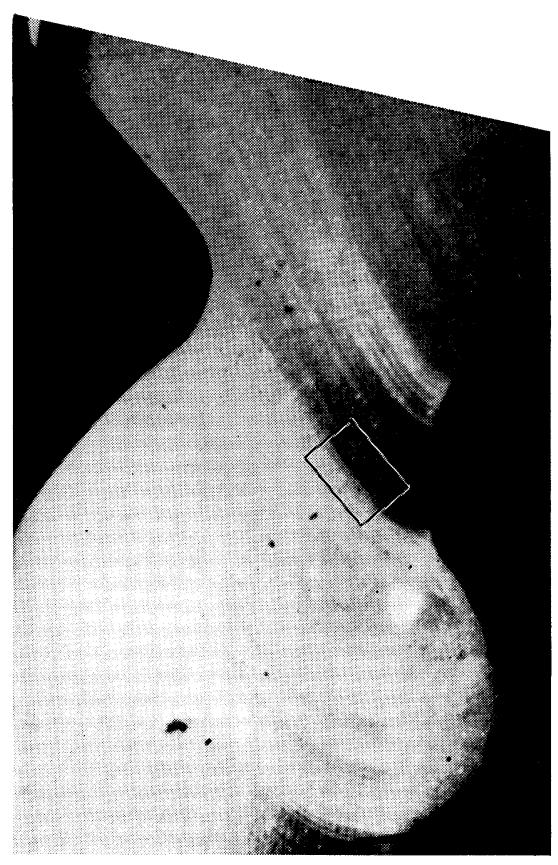

Fig. 8 (B)

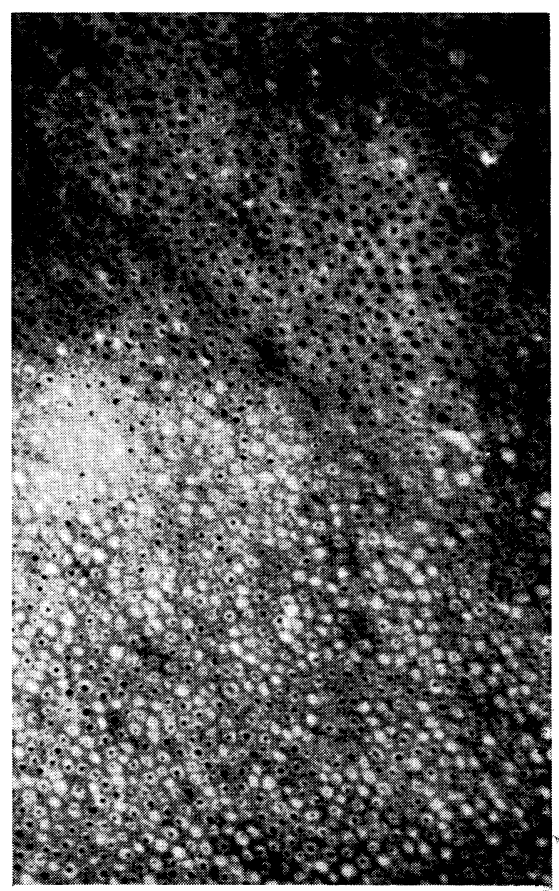

Fig. 8 (D) 
[6] Isokawa, S. and Shimoyama, T. : Peritubular Hypercalcified Zone of Some Mammalian Dentinal Tubules (Japanese Abst.) Acta Anat. Nipp., 40:5, Supplement p. 6 (1965).

[7] Shimoyama, T. : Peritubular Hypercalcified Zone of Mammalian Dentin, Arch. histol. jap., unpublished thesis.

[18] FeILeR, E. : Die Transparenz des Zahnbeins, Zschr. Stomat., 21: 595-614 (1923). 